\title{
MECHANICAL AND MICROSTRUCTURAL PROPERTIES OF PLLA / TPS / GELATIN EXTRUDED SHEETS
}

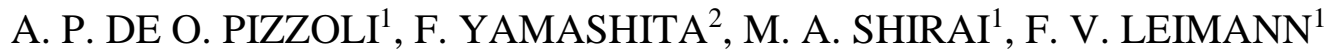 \\ ${ }^{1}$ Programa de Pós Graduação em Tecnologia de Alimentos, Universidade Tecnológica Federal do \\ Paraná, Campus Campo Mourão (UTFPR-CM), PR, Brasil; \\ ${ }^{2}$ Departamento de Ciência e Tecnologia de Alimentos, Universidade Estadual de Londrina (UEL), \\ PR, Brazil. \\ E-mail para contato: fernandaleimann@utfpr.edu.br
}

\begin{abstract}
Poly (L-lactic acid) (PLLA) and thermoplastic starch (TPS) have been largely applied in the biodegradable packaging development in order to reduce residues generated from traditional packaging. Besides these biopolymers gelatin is also an interesting biomaterial for the production of films by extrusion. In this work, blends of PLLA, TPS (glycerol as plasticizer) and different concentrations of gelatin (0, 3 and 5wt $\%$ in relation to TPS) were produced in a double twin-screw co-rotating extruder coupled to a roll laminator. Films mechanical properties were determined in texture analyzer and their microstructure by Scanning Electron Microscopy. The formulations without and with $5 \mathrm{wt} \%$ of gelatin showed smoother surfaces. The intermediate formulations showed porous surface with non-plasticized starch granules. The fracture of all produced films showed voids in the structure. In general, the addition of gelatin at the films leaded to a hardness and tensile strength reduction.
\end{abstract}

\section{INTRODUCTION}

Applications of biopolymers as environmental friendly packaging materials were studied extensively (Heydari at al., 2013). However, there is an increasing demand for identifying biodegradable packaging materials and finding innovative methods to make plastic degradable. Biodegradation is the process by which carbon-containing chemical compounds are decomposed in the presence of enzymes secreted by living organisms (Mahalik and Nambiar 2010). Plastics currently used for food packaging such as low-density polyethylene (LDPE) and polypropylene are synthesized from petroleum-based chemicals and they are nondegradable. The wastes of material produced from petroleum-based polymer have brought negative impact not only for human being, but also generate serious environmental problems (Kuchaiyaphum et al., 2013).

Among the biodegradable material studied until now in the literature, poly(L-lactic acid) (PLLA) has received increasing attention due to their natural biodegradability which made it interesting for biomedical, pharmaceutical, and food applications (Siracusa et al., 2012). PLLA is safe and generally recognized as safe for its use in contact with food, approved from the Food and Drug Administration (Conn et al., 1994). 


\section{9 a 22 de outubro de 2014 \\ Florianópolis/SC}

Another versatile biomaterial is gelatin, obtained from collagen by the controlled hydrolysis of the fibrous insoluble collagen present in the bones and skin generated as waste during animal slaughtering and fish processing (Ahmad et al., 2012). In general, protein films are effective lipid, oxygen, and aroma barriers at low relative humidity (Bai et al., 2013).

One of the most investigated biopolymers is starch, owing to its wide availability, good biodegradability as well as low cost (Heydari et al., 2013). Native starch is one of the most naturally abundant biopolymers. The starch granule is essentially composed of two main polysaccharides, amylose and amylopectin, and some minor components such as lipids and proteins. However, several authors have pointed out that, despite their ease of preparation, starch-based films present some drawbacks, such as their poor mechanical properties which make the addition of plasticizing compounds necessary (Peressini et al. 2003; Bravin et al., 2006). Starch granules can be gelatinized in the presence of a plasticizer (thermoplastic starch, TPS) and heat during wich the crystalline structure is disrupted. This allows the starch to flow at high temperatures allowing it to be processed by conventional equipment (eg. Extrusion) (Taghizadeh et al., 2013). The most used technique today for the production of bioplastics is casting; however, one of the problems with films produced by this technique is the limitation on the quantity produced (Fakhouri et al., 2013). Extrusion is the most used technique for large-scale production of polymeric packaging. Thus, the research on extrusion processing of biopolymers presents relevance for practical application.

Blending starch with other biopolymers can improve its poor mechanical properties (Bonilla et al., 2013). The development of blends composed by starch and gelatin has attracted the attention of several research groups (Al-Hassan and Norziah, 2012; Zhang et al 2013; Liu et al., 2014; Fakhoury et al., 2012; Fakhoury et al., 2013). Arvanitoyannis et al. (1998) concluded that blended films of polysaccharide and protein showed better gas barriers $\left(\mathrm{O}_{2}\right.$ and $\left.\mathrm{CO}_{2}\right)$ than any of the pure films. Blends composed by PLLA and gelatin have been used to develop electrospun fibers (Chiou et al., 2013; Yang et al., 2010) and films (Zhao et al., 2006). However, few reports can be found about the production and characterization of blends composed by starch, PLLA and gelatin. An example is the work of Guzman-Sielicka et al., 2013, that obtained polymer blends composed by poly(lactic acid), starch, calcium carbonate, gelatin and glycerol by thermopressing. The authors submitted the produced materials to degradation testes under marine aquarium conditions and concluded that gelatin was the key-component which contributed and enhanced the fragmentation of polymer films.

The objective of the present work was to produce biodegradable sheets composed by PLLA, TPS and gelatin by extrusion and calendering process and evaluate their mechanical properties and microstructure in function of gelatin amount incorporated.

\section{MATERIALS AND METHODS}

\subsection{Materials}

PLA Ingeo 4043D (Natureworks LLC, Cargill, USA), cassava starch (Indemil, Brazil), glycerol (Dinâmica, Brazil) as plasticizing for the starch and gelatin (Dinâmica, P.A., Brazil) were used to produce the extruded blend sheets. Magnesium nitrate (Vetec, Brazil) was used to control the relative 
humidity during sheets conditioning.

\subsection{Production of pellets and sheets}

The procedure adopted was described by Shirai (2013) and the sheets formulations are presented in Table 1. In the control formulation (FC) gelatin was not added, and in FG3 and FG5 formulations the gelatin percentage (wt\%) is related to TPS mass (starch and glycerol) ranging from 3 to $5 \mathrm{wt} \%$. The proportion between starch and glycerol was maintained in all formulations $(33 \mathrm{~g}$ glycerol/100g starch).

For the sheets production, initially gelatin was allowed to gelatinize in contact with glycerol during 24 hours at room temperature. After that the other blend components were manually mixed and extruded as cylindrical profiles in a co-rotating twin-screw extruder (BGM, D-20 model, Brazil) using the following processing conditions: a screw diameter of $20 \mathrm{~mm}(\mathrm{~L} / \mathrm{D}=35)$, a screw speed of $100 \mathrm{rpm}$, a feeder speed of $30 \mathrm{rpm}$, and a temperature profile of $100 / 180 / 180 / 180 / 180^{\circ} \mathrm{C}$ at the 5 zones. The extruded cylindrical profiles were cooled at room temperature and were pelletized.

The obtained pellets were extruded in the same twin-screw extruder coupled with a calendar (AX-Plásticos, Brazil) for sheets production. The temperature profile was $100 / 170 / 170 / 170$ / $175^{\circ} \mathrm{C}$, and the screw speed and feed speed were maintained. In the calender, the distance between the rolls was $0.8 \mathrm{~mm}$, and the roll speed was adjusted depending on the formulation to maintain continuous processing.

Table 1 - Composition of the PLLA/TPS/gelatin extruded sheets

\begin{tabular}{cccccc}
\hline Formulation & $\begin{array}{c}\text { Gelatin } \\
(\mathrm{wt} \%)\end{array}$ & PLLA $(\mathrm{g})$ & Starch $(\mathrm{g})$ & Glycerol $(\mathrm{g})$ & Gelatin $(\mathrm{g})$ \\
\hline FC & 0 & 250.00 & 187.50 & 62.50 & 0.00 \\
FG3 & 3 & 250.00 & 181.88 & 60.63 & 7.50 \\
FG5 & 5 & 250.00 & 178.13 & 59.37 & 12.50 \\
\hline
\end{tabular}

\subsection{Mechanical properties}

The tensile strength tests were performed with a texture analyzer (Stable Micro Systems, TA XTplus model, England) based on the American Society for Testing and Material standards (ASTM, 2002). The samples were previously conditioned at $23 \pm 2{ }^{\circ} \mathrm{C}$ and $53 \pm 2 \%$ of relative humidity for 48 $\mathrm{h}$. The properties measured were tensile strength $(\mathrm{MPa})$, elongation at break $(\%)$, and Young's modulus $(\mathrm{MPa})$.

\subsection{Scanning electron microscopy (SEM)}

The microstructure of the surface and fractured sheets was analyzed with a scanning electron microscope (Philips, XL-30 model, Holland) with electron source of tungsten and detectors of secondary and backscattered electrons. The sheets were immersed in liquid nitrogen and then broken. 
The samples were coated with gold using a sputter coater (BALTEC, SCD 005 model, Switzerland). All the samples were examined using an accelerating voltage of $10 \mathrm{kV}$.

\subsection{Statistical analysis}

The mechanical properties results were evaluated using analysis of variance (ANOVA), and treatment means were compared using Tukey's test at the 5\% significance level $(\mathrm{p}<0.05)$ with Statistica 7.0 software (Stat-Soft, Tulsa, OK, USA).

\section{RESULTS AND DISCUSSION}

Considering visual aspects, the PLLA/TPS/gelatin extruded sheets were rigid, opaque and yellowish probably due alignment of polymers chain and crystallization induced by extrusion process.

Figure 1 shows the SEM micrographs of the PLLA/TPS/gelatin sheets surface and fractures. It is possible to observe the presence of non-gelatinized starch granules at the surface of all sheet formulations and that smoother surfaces were obtained for the formulations without gelatin (FC) and with $5 \mathrm{wt} \%$ of gelatin. The intermediate formulation (FG3) presented a more irregular and porous aspect. Similar results were observed by Zhang et al. (2013) that produced films of gelatin and starch. The authors observed some protrusions on the surfaces of the films and that the density of these protrusions increased with increasing starch content. As the films were produced by casting technique it is suggested that gelatin and starch are two phases, and that the shrinking ratios of gelatin and starch are different during drying. In the case of the present work the shrinking ratio of gelatin and starch after extrusion could be different during the chilling step. Guzman-Sielicka et al. (2013) produced blends of PLLA, gelatin and starch by thermopressing and observed an increase in the porosity with the increase in the concentration of gelatin. Probably the same effect was not observed at Figure 1 because at this study the amount of gelatin applied in the formulations (up to $2.5 \mathrm{wt} \%$ related to the total formulation) was lower than by Guzman-Sielicka et al. (2013) (from 10 to 40wt\% related to the total formulation). 

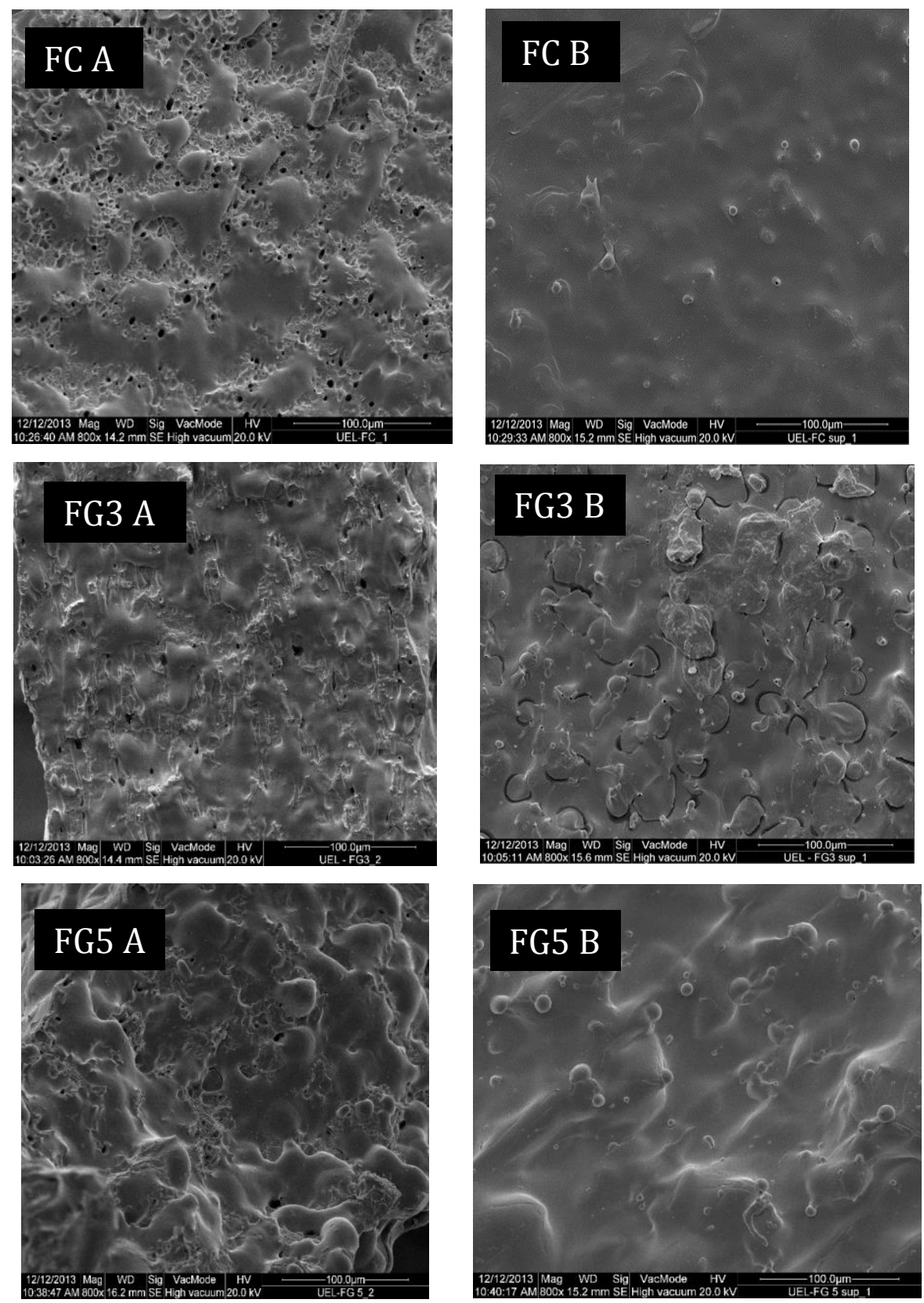

Figure 1- Micrographs of the fracture (A) and surface (B) (800x) of the PLLA, TPS and gelatin sheets.

The mechanical properties results in terms of tensile strength, Young's modulus and elongation at break are presented in Table 2. The gradual addition of gelatin in PLLA/TPS sheets significantly affected the mechanical properties. A decrease of about $30 \%$ was observed in tensile strength, Young's modulus and elongation of break and this fact can be explained due to the incompatibility 


\section{9 a 22 de outubro de 2014 \\ Florianópolis/SC}

between the components of the blend. The mechanical properties of the sheets are directly linked to interfacial adhesion between the polymers of the blend. When the polymers are mixed, it is interesting that the dispersion and the distribution of the particles occur, forming a single polymeric phase. Poor dispersal could result in the formation of clusters from the entanglement of the polymer chains, which reduces the transmission of tension (Bradelero et al., 2011). In the SEM images observed before, the presence voids and non-gelatinized starch granules difficult the load transfer under stress explaining the results obtained.

Table 2 - Mechanical properties of PLLA/TPS/gelatin extruded sheets

\begin{tabular}{cccc}
\hline Formulation & $\begin{array}{c}\text { Tensile Strength } \\
(\mathbf{M P a})\end{array}$ & $\begin{array}{c}\text { Elongation at break } \\
(\boldsymbol{\%})\end{array}$ & $\begin{array}{c}\text { Young's Modulus } \\
(\mathbf{M P a})\end{array}$ \\
\hline FC & $28.8 \pm 2.1^{\mathrm{a}}$ & $31.7 \pm 6.1^{\mathrm{a}}$ & $614 \pm 51^{\mathrm{a}}$ \\
FG3 & $22.7 \pm 0.9^{\mathrm{b}}$ & $36.0 \pm 9.7^{\mathrm{a}}$ & $520 \pm 39^{\mathrm{b}}$ \\
FG5 & $19.8 \pm 0.8^{\mathrm{c}}$ & $20.5 \pm 3.1^{\mathrm{b}}$ & $483 \pm 25^{\mathrm{b}}$ \\
\hline
\end{tabular}

$\mathrm{a}, \mathrm{b}$ The averages followed by the same letters in the same column do not exhibit differences at the 5\% significance level according to Tukey's test.

Films made from blends of cassava starch and gelatin by casting technique presented increased tensile strength as gelatin was added, due their reinforcement properties to the polymeric matrix (Fakhoury et al., 2012; Fakhoury et al., 2013). In our study similar results were not observed, because of the presence of hydrophobic polymer like PLLA and their incompatibility between starch and gelatin as related in other studies (Shirai, 2013; Zhao et al., 2006). Although starch and gelatin are hydrophilic and compatible, they are immiscible and presented as two phases (Liu et al., 2014).

Several reports describes the production of PLLA/gelatin blend and TPS/gelatin blends by casting methods (Fakhoury et al., 2012; Fakhoury et al., 2013; Liu et al., 2014). The main problem with films produced by this technique is the limitation on the quantity produced, and the use of solvents to disperse the components. Although the gelatin addition affected the sheets mechanical properties, it was possible to produce them by extrusion and calendering process at pilot scale and could be an alternative to offer biodegradable packaging for low moisture foods in commercial scale.

\section{CONCLUSIONS}

The extrusion and calendering process were feasible way to produce PLLA/TPS/gelatin blended sheets with interesting functional properties. The incorporation of gelatin in PLLA/TPS blends affected significantly the mechanical properties by rigidity reduction, and SEM images revealed the incompatibility between PLLA, starch and gelatin.

\section{ACKNOWLEDGEMENTS}

The authors thank Fundação Araucária, CAPES, CNPq for their financial support, and Microscopy Laboratory of UEL for the use of scanning electron microscope. 


\section{REFERENCES}

AHMAD, M.; BENJAKUL, S.; PRODPRAN, T.; AGUSTIN, T.W. Physico-mechanical and antimicrobial properties of gelatin film from the skin of unicorn leatherjacket incorporated with essential oils. Food Hydrocolloidi., v. 28, p.189-199, 2012.

AL-HASSAN, A. A.; NORZIAH, M. Starch-gelatin edible films: Water vapor permeability and mechanical properties as affected by plasticizers. Food Hydrocolloid., v. 26, p. 108-117, 2012.

ARVANITOYANNIS, I.; NAKAYAMA, A., AIBA, S. Edible films made from hydroxypropyl starch and gelatin and plasticized by polyols and water. Carbohyd Polym., v. 36, p. 105-119, 1998.

BAI, H.; XU, J.; LIAO, P.; LIU, X. Mechanical and water Barrier properties of soy protein isolate film Incorporated with gelatin. J. Plast. Film Sheet., v. 29, n. 2, p. 174-188, 2013.

BONILLA, J.; ATARÉS, L.; VARGAS, M.; CHIRALT, A. Properties of wheat starch filmforming dispersions and films as affected by chitosan addition. J Food Eng, v. 114, p. 303-312, 2013.

BRANDELERO, R. P. H.; GROSSMANN,M.V.E .; YAMASHITA, F. Effect of the method of production of the blends on mechanical and tructural properties of biodegradable starch films produced by blown extrusion. Carbohyd Polym., v. 86, p. 1344-1350, 2011.

CHIOU, B. S.; FRI, H. J.; BUSTILLOS, R. A.; GREGORSKI, K.S.; BECHTEL, P.J.; IMAM, S.H.; GLENN, G.M.; ORTS, W.J. Properties of electrospun pollock gelatin/poly(vinyl alcohol) and pollock gelatin/poly(lactic acid) fibers . Int J Biol Macromol., v. 5, p. 214-220, 2013.

CONN , R. E.; KOLSTAD, J. J.; BORZELLECA , J. F.; DIXLER , D. S.; FILER, L. J.; La Du, Jr. B. N.; PARIZA , M. W. Safety Assessment of Polylactide (PLA) for Use as a Food-contact Polymer. Fd. Chem. Toxic., v. 33, p. 273-283, 1995.

FAKHOURI, F. M.; DARYNE, C.; YAMASHITA, F.; MARTELlI, S. M.; JESUS, R. C.; ALGANER, K.; QUEIROZ, F. P. C.; MEI, L. H. I. Comparative study of Processing methods for starch/gelatin films. Carbohy. Polym., v. 95, p. 681-689, 2013.

FAKHOURY, F. M.; MARTELLI, S. M.; BERTAN, L. C.; YAMASHITA, F.; MEI, L. H. I.; QUEIROZ, F. P. C. Edible films made from blends of manioc starch and gelatin: Influence of different types of plasticizer and different levels of macromolecules on their properties. Food Sci. Technol. Int., v. 49, p. 149-154, 2012. 
GUZMAN-SIELICKA, A.; JANIK, H.; SIELICKI, P. Proposal of New Starch-Blends Composition Quickly Degradable in Marine Environment. J. Polym. Environ., v. 21, p. 802-806, 2013.

HEYDARI, A.; ALEMZADEH, I.; VOSSOUGHI, M. Functional properties of biodegradable corn starch nanocomposites for food packaging applications. Mater. Design.,v. 50, p. 954-961, 2013.

KUCHAIYAPHUM, P.; PUNYODOM, W.; WATANESK, S.; RUANGSRI W. R. Composition Optimization of Polyvinyl Alcohol/Rice Starch/Silk Fibroin-Blended Films for Improving Its Eco-Friendly Packaging Properties. Appl. Polym.sci,. v. 129, n. 5, 2013.

LIU, Y. S.; HUANG, Q. L.; KIECZLE, E. A.; MULLER, W. E. G.; FENG, Q. L. In vitro degradation of porous PLLA/pearl powder composite scaffolds. Mater Sci Eng., v. 38, p. 227234, 2014.

MAHALIK, N. P.; NAMBIAR, A. N. Trends in food packaging and manufacturing systems and technology. Trends Food Sci Tech., v. 21, p. 117-128, 2010.

PERESSINI, D.; BRAVIN, B.; LAPASIN, R.; RIZZOTTI, C.; SENSIDONI, A. Starchmethylcellulose based edible films: rheological properties of film-forming dispersions. $J$. Food Eng., v. 59, p. 2-32, 2003.

SHIRAI, M. A.; GROSSMANN, M. V. E.; YAMASHITA, F.; GARCIA, P. S.; MÜLLER, C. M. O. Development of biodegradable flexible films of starch and poly ( lactic acid ) plasticized with adipate or citrate esters. Carbohyd. Polym., v. 92, n. 1, p. 19-22, 2013.

SIRACUSA, V.; BLANCO, I.; ROMANI, S.; TYLEWICZ, U.; ROCCULI, P.; Poly(lactic acid)-Modified Films for Food Packaging Application: Physical, Mechanical, and Barrier Behavior. J Appl Polym Sci., v. 125, p. 390-401, 2012.

TAGHIZADEH, A.; SARAZIN, P.; FAVIS, B. D. High molecular weight plasticizers in thermoplastic starch/ polyethylene blends. J Mater Sci ., v. 48, p. 1799-1811, 2013.

YANG, X.; XU, Q.; YAN, N.; SUI, G.; CAI, Q.; DENG, X. Structure and wettability relationship of coelectrospun poly (L-lactic acid)/gelatin composite fibrous mats. Polym. Adv. Technol., v. 22, p. 2222-2230, 2010.

ZHANG, N.; LIU, H.; YUA, L.; LI, X.; ZHANG, L.; CHEN, L.; SHANKS, R. Developing gelatin-starch blends for use as capsule materials. Carbohyd Polym., v.92, p. 455-461, 2013.

ZHAO, X.; LIU, W.; YAO, K. Preparation and Characterization of Biocompatible Poly(L -lactic acid)/Gelatin Blend Membrane. J. Appl. Polym. Sci., v. 101, p. 269-276, 2006. 